\title{
Correction to: A reliable energy-aware approach for dynamic virtual machine consolidation in cloud data centers
}

\section{Monireh H. Sayadnavard ${ }^{1}$. Abolfazl Toroghi Haghighat ${ }^{2}$. Amir Masoud Rahmani ${ }^{1}$}

Published online: 13 February 2019

(c) Springer Science+Business Media, LLC, part of Springer Nature 2019

\section{Correction to: The Journal of Supercomputing https://doi.org/10.1007/s11227-018-2709-7}

The spelling of Monireh H. Sayadnavard's family name was incorrect. The correct wording is given here. The original article has been corrected.

The original article can be found online at https://doi.org/10.1007/s11227-018-2709-7.

Abolfazl Toroghi Haghighat

at_haghighat@yahoo.com; haghighat@qiau.ac.ir

Monireh H. Sayadnavard

mo.sayadnavard@gmail.com

Amir Masoud Rahmani

rahmani@srbiau.ac.ir

1 Department of Computer Engineering, Science and Research Branch, Islamic Azad University, Tehran, Iran

2 Faculty of Computer and Information Technology Engineering, Qazvin Branch, Islamic Azad University, Qazvin, Iran 